\title{
Professional Practice: A Case Study of Collaborations between Education and Industry
}

\author{
Shahrukh Ashruf ${ }^{1}$, Daniel van der Plaats ${ }^{1}$, Hani Al-Ers ${ }^{2}$, Aleksandra Malinowska ${ }^{3}$, and Xiao Peng ${ }^{4 *}$ \\ 1.The Hague University of Applied Sciences, The Netherlands \\ 2.Faculty IT \& Design, The Hague University of Applied Sciences, The Netherlands \\ 3.University of California, Santa Barbara, California, USA \\ 4.Faculty Business, Finance and Marketing, The Hague University of Applied Sciences, The Netherlands
}

\begin{abstract}
Collaboration between university and industry has brought societal and educational benefits by promoting research and innovation, providing industry training, and promoting access to resources and technology for both academia and industry. University, industry, and government collaboration known as the triple helix was proposed in the 1990s. However, industry and university collaboration has had a long history with best practices being updated as we learn more about specific fields, needs of collaborators, and advances in research and technology.This case study aims to find the best practices for collaboration between education and industry in a project-based educational program known as Professional Practice for students studying in the field of information technology. During this four-week program, students worked on assignments formulated by the participating companies. They were guided by company-assigned supervisors, who were interviewed before and after the program. The students too were asked to fill out surveys before and after the program. From the analyses of the results of the interviews and surveys, several recommendations and ways to improve collaboration between education and industry are presented.
\end{abstract}

Keywords: triple helix, collaboration, education, industry, project-based learning

DOI: $10.7176 / \mathrm{JEP} / 12-6-10$

Publication date: February $28^{\text {th }} 2021$

\section{Introduction}

The collaboration between industry and education is an important part of innovation. Education needs to stay relevant to developments in the industry, while the industry needs the knowledge and insight from the education sector to overcome real-world obstacles and prevent future difficulties (Ankrah and AL-Tabbaa, 2015; Rynes et al., 2001). Additionally, collaboration between universities and the industry is regarded as a significant source of knowledge and technology acquisition. In a competitive market, the emphasis on more advanced products increasingly builds the need for effective collaboration (Ankrah and AL-Tabbaa, 2015; Rynes et al., 2001).

\section{Current state of education}

According to Uziak (2016), engineering is a field where technical and work-field related developments are frequently made. This results in an increased need for better social, organizational, and collaboration skills for new graduates. However, today's engineering industry is not satisfied by the current professional abilities of new graduates. Since the majority of current education puts emphasis on technical knowledge, new graduates often experience difficulty adapting to a new work environment (Crosthwaite et al., 2006). As Kobayashi (2020) describes, students may be unprepared for the global workforce by lacking training in English or understanding globalized industry. Not only does the engineering industry express the need for better professional skills from students, Vande Wiele et al. (2017) indicated that the development of professional identity is a frequent point of debate in the Marketing sector as well. Higher education lacks the support for advancing students' professional behaviours and professional identity. For these reasons, innovation in the current education curricula is important.

To improve students' general and social abilities, lectures and traditional learning will not suffice. Students learn these skills by repeated practice, as needed, and through presented opportunities. One way to help students develop these abilities, is to integrate a more project-focused educational approach (Crosthwaite et al., 2006).

The traditional approach of education has been used for decades and is still applied in several fields. This approach consists of letting the student learn the material and testing their knowledge by solving relevant problems. This may be effective for technical knowledge, however in order to develop professional skills a more project-focused educational approach is needed.

\section{University-industry collaboration}

Collaboration between education and industry can procure many possible benefits for students, the industry, and the university. For students, the main benefit is personal development and preparation for the workforce, the university benefits by understanding the needs of the business sector, and industry gains newer and broader theoretical knowledge for their sector (Slotte and Tynjälä, 2003). This type of collaboration is one part of the 
triple helix concept of innovation (Etzkowitz and Leydesdorff, 1995).

The possible gains from effective collaboration come with several challenges. As the work of Slotte and Tynjälä (2003) proposes, two of these challenges are the lack of collaboration opportunities and differences in educational perspectives. To elaborate on the last point, industry and universities often differ in their views on the best educational approach. Even in such a case, it is possible to find a shared understanding between all involved stakeholders (academics, industry, as well as students) (Goldsmith et al., 2011).

Other times new educational approaches prove successful, yet have difficulty being implemented in other departments of schools and universities. In order to do so, strategies to incorporate the approach into the course structure need to be developed, which requires senior staff members to be involved in creating a detailed plan for their department (Dunne and Rawlins, 2000).

The interests of universities and industry overlap in several fields. For example, both parties will profit from research, universities from project research and industry from practical research (Ivascu et al., 2015). Furthermore, both the universities and the industry have a common interest in reputation, universities by publications and industry by revenue (Ivascu et al., 2015). These shared interests can be a motivator to research more effective collaboration.

Two educational approach alternatives, project-based learning and problem-based learning, are implemented in a number of fields and universities (Mills and Treagust, 2003). While the implementation of project-based learning has been well documented in a plethora of fields, studies regarding these approaches in IT $\&$ Design are less common than in the engineering field. Since this study is about improving collaboration between education and industry, it was decided to focus on project-based learning rather than problem-based learning, due to problem-based learning mostly involving students without much input from companies.

\section{Project-based learning (PBL)}

An alternative to the traditional education method is PBL. This method involves students working on a project with predetermined goals in mind. The goal is to develop a product or perform research specific to a real-world problem. The final product is then evaluated for a grade.

Changing an educational approach can be difficult. According to two case studies in 2013, PBL allows students to work more collaboratively by being engaging and motivating (Chandrasekaran et al., 2013; Tamim and Grant, 2013). A case-study by Tamin and Grant (2013) found that teachers that implemented PBL reacted positively to the new change to the curricula. Another case-study by Crosthwaite et al. (2006) reviewed the chemical engineering curricula and changed it to be project-centered. The result was a successful framework for a new project-centered curriculum. This curriculum received endorsement from both the educational and professional sectors

As Vande Wiele et al. (2017) concluded, the implementation of PBL will improve the professional behavior of new graduates. The result of implementing PBL was that students were more employable and had better communication skills in the work-field. This increase in better employable students lessens the gap between education and industry.

\section{Professional Practice (PP)}

Professional Practice is an educational program that makes use of PBL. This involves Dutch IT \& Design students working for a company on assignments that they can expect in the work-field. This differs from teaching models as described by Rosemann et al. (2000) in that assignments are chosen by the companies, which have to be related to IT.

PP has a duration of 4 weeks, during which the students work to earn study credits and, depending on the agreement, get financial compensation.

This case study aims to find the best practices for a project-based course in the IT \& Design curriculum. These practices can help guide and improve collaboration between education and industry. This is done by evaluating the course of the project and identifying key aspects to improve collaboration. Therefore, the main research question is: "What are the best practices for collaboration between education and industry in Professional Practice?"

\section{Methodology}

The research question is answered by performing a case study. This study observes IT \& Design students from The Hague University of Applied Sciences that start the professional practice class. Over the span of four weeks, students work on a project specified by a company. Companies have free choice for the assignment specifics, however it must be related to IT \& Design. Assignments are classified to one of the five provided themes.

The first theme, Risk Analysis, involves the students running a risk analysis to find information security risks. Students then give advice to reduce these newfound risks. Another theme is a penetration test, where students try to determine if hackers can penetrate certain websites or company systems. The students report this, 
along with recommendations for prevention of breaches. The third theme is Social Engineering, where students observe employees of the company with regard to the regulations of information security. The fourth theme is an Awareness Campaign, which involves running a culture analysis and raising awareness to the company's employees about their information security. The final theme is a custom theme, which the company can determine. This theme can range from privacy to security operations.

Researching a topic such as collaboration between academics and industry often involves surveys or questionnaires (Davis, 2002; Sageev and Romanowski, 2001; Wrzesien and Raya, 2010).

\subsection{Data from the companies}

The participating students were assigned supervisors from the company to guide the students over the course of the assignment. These supervisors of the participating companies are interviewed before and after the assignment. The questions asked before the professional practice period are mainly about the companies' expectations of the assignments, students, and challenges (e.g. "What challenges do you expect to face during PP?").

Other questions focus on the preparations and assignment criteria which the companies have applied. These questions help with understanding the companies' view when starting the assignment. Questions like: "What preparations did you make to have students work in the company?". After the assignment period, the answers can be re-evaluated and it can give insight whether expectations were met.

After the assignment period the supervisors are interviewed again. Similar to the previous interviews, questions are asked about their expectations. More specifically, if their expectations were met on different subjects.

Multiple questions are asked surrounding feedback (e.g. "Would you recommend professional practice for other companies? And why?").

\subsection{Data from the students}

Student participants are all male and have an age range of 19 to 23 years old. These students are all enrolled in a study program focused on IT and Design. The participating students are given the voluntary option to fill in a survey before and after professional practice. These surveys are given in Dutch to the students, however in the analysis in Section 3.2.2 the English translation is used. This is done to gain the insight of the students during PP. Every survey starts by asking the student to record their age, sex, study year, the name of their assignment's company, their assigned task, and finally their role in completing that task.

The survey filled in before the project contained questions in the form of statements regarding PP. The students rate on a scale from -2 to 2 how much they agree with the given statement. One example of such a statement is: "I am convinced that Professional Practice is a positive influence on my development regarding the subject".

After the project, students fill in a similar survey. In addition to the questions of the previous survey, this survey presents new questions to the students. A number of these are open questions where the student can give their input. An open question in the survey is for example: "Do you have any recommendations for Professional Practice?”.

\section{Analysis \& results}

\subsection{Qualitative analysis}

3.1.1 Qualitative analysis of the pre-interviews

Prior to the start of PP, five of the participating companies were interviewed. The answers provided the companies' predictions and expectations regarding professional practice. To analyze these answers, they were split into singular statements and labeled with keywords. When labeling these statements, several similarities became apparent. The similar keywords formed categories that were used to create a mind-map of the preinterviews. This mind-map is shown in Figure 1. To help illustrate the meaning of the different categories in the figure, a brief summary is given per category in Table 1. 


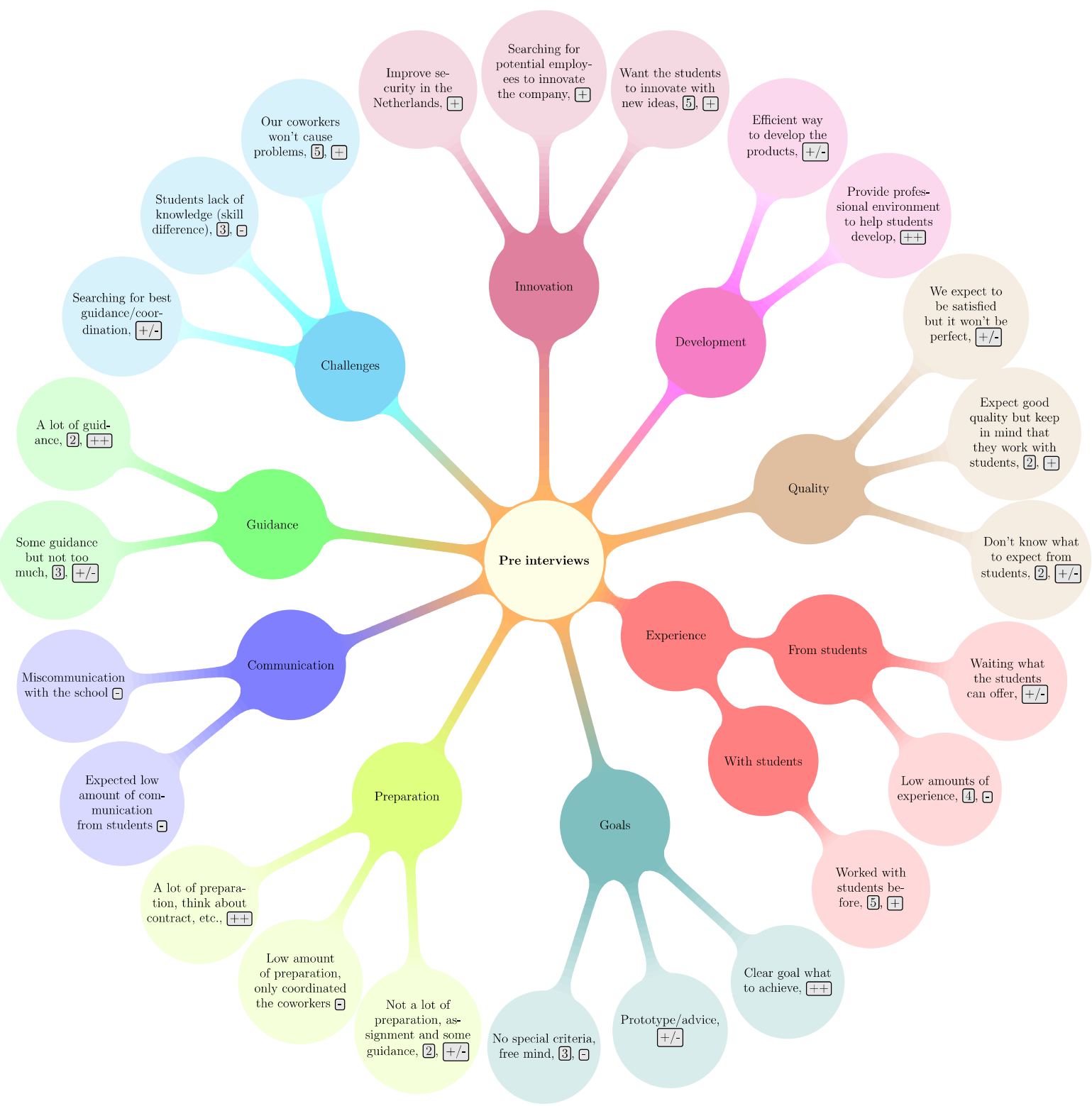

Figure 1. Mind-map of the qualitative analysis from the pre-professional practice interviews. The numbers in the outer layers indicate how many times a statement linked to the displayed keyword appeared. The plus and minus symbols indicate whether this was used in a positive $(+)$ or negative $(-)$ context. 
Table 1. A summary of each keyword category as shown in Figure 1. The Development category is not listed, because its keywords in Figure 1 describe it sufficiently.

Communication Expectations and experiences thus far relating to communication are displayed in this category. In general, the companies had negative expectations and experiences with communication. In one instance there was miscommunication between the school and company regarding the participating students. Furthermore, the companies expect there to be low levels of communication with students.

Preparation

This category describes the preparations that the company implemented prior to the assignment period. The preparations ranged from a low amount to a lot. Common preparations which were made are accessing work credentials and utilities, setting up the contract, planning meetings and coordination.

Goals

The "Goals" category displays all the goals the companies hope to achieve with professional practice. When asked about the goals they hope to achieve, the majority answered to have no specific criteria and would keep an open mind. One company indicated they wanted advice from the students on a prototype.

Experience $\quad$ This category is split into two subcategories. One describes the companies' experience with students, while the other describes the expectations of the students' experience in the work field.

All companies answered to have worked with students before at one point. The expectation of the students' experience was, for 4 out of 5 companies, low. This also explains why a lack of students' knowledge is an expected challenge.

Quality

After the assignment period, the students submit their final product. The expectations and opinions on the quality of this product is found under this category. The opinions on the quality of the final product were split. Two companies expect good quality, while two other companies did not know what to expect. The companies all indicated they kept in mind that they work with students for this assignment.

Innovation

In the "Innovation" category, the new changes and ideas the companies hope to create are displayed. The most mentioned subjects from the companies involved innovation. The companies agreed that they want the students to innovate with new ideas. In Figure 1 this is the keyword: "Want the students to innovate with new ideas".

Challenges

When asked which challenges the companies expect to face, two different challenges were mentioned. Searching for the right guidance to give the students was a challenge that the companies expect to face.

Guidance

This category describes how much guidance the companies expect to give the students. Expectations surrounding guidance varied, three of the five companies expect to give some guidance but not too much. The other two companies expect to give a lot of guidance.

\subsubsection{Qualitative analysis of the post-interviews}

After the PP period the companies were interviewed to give final thoughts and feedback on PP. The questions that were asked all involved multiple themes surrounding the execution, performance, final product and many other aspects of PP. The companies also responded to open answers and those answers are taken into consideration in this analysis. The answers were analyzed in the same way described in Section 3.1.1. 


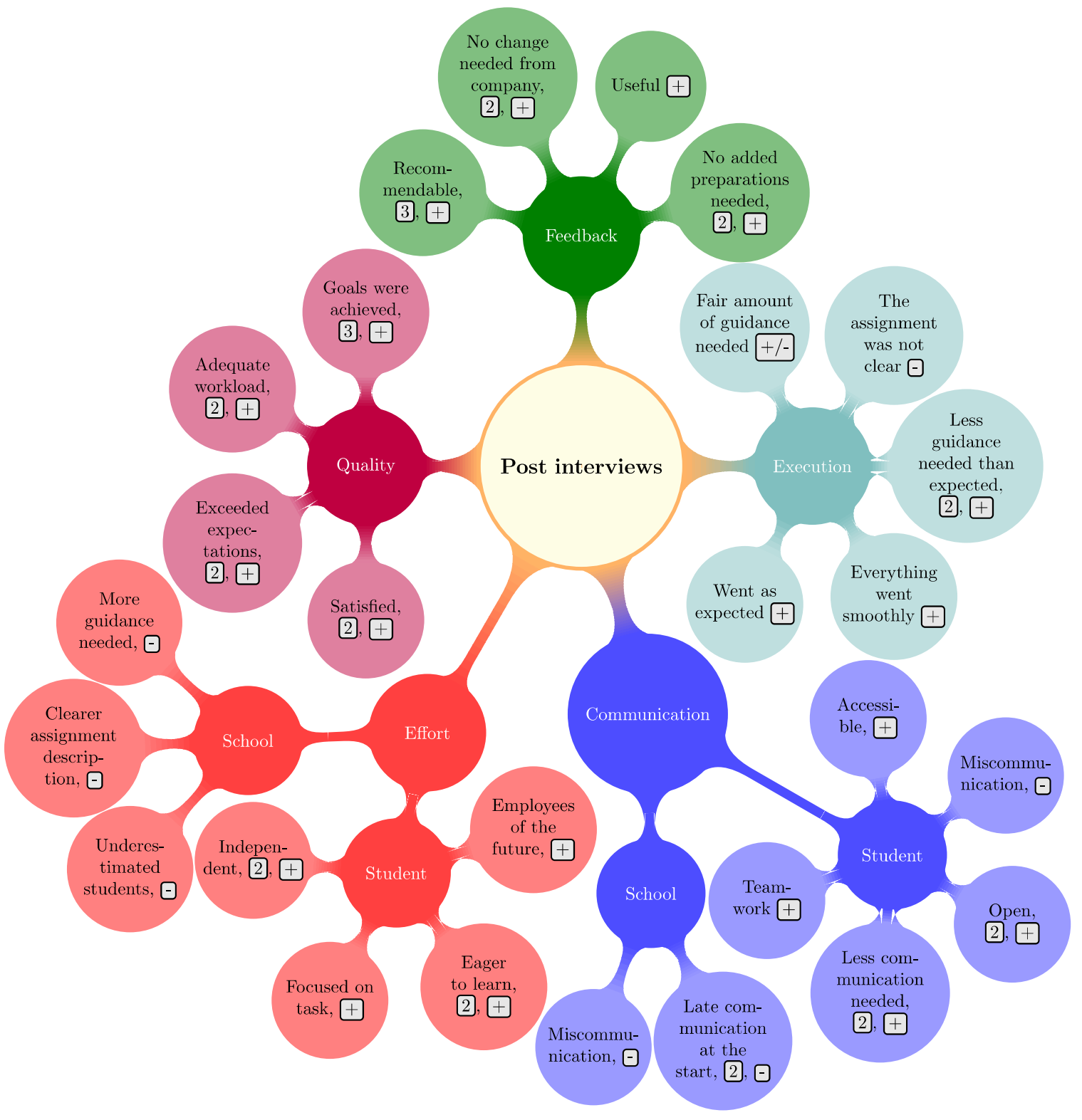

Figure 2. Mind-map of the qualitative analysis from the post-professional practice interviews. The numbers in the outer layers indicate how many times a statement linked to the displayed keyword appeared. The plus and minus symbols indicate whether this was used in a positive $(+)$ or negative $(-)$ context.

To help clarify the mind-map shown in Figure 2, each category is addressed in Table 2. 
Table 2. A summary of each keyword category as shown in Figure 2.

\begin{tabular}{|c|c|}
\hline Feedback & $\begin{array}{l}\text { Feedback on the structure of Professional Practice is given in this category. To } \\
\text { elaborate, this category presents the feedback on the effectiveness of the project and } \\
\text { lists any points of improvement. } \\
\text { All companies indicated that PP is recommendable for the future. According to the } \\
\text { companies, no added changes are needed. }\end{array}$ \\
\hline Quality & $\begin{array}{l}\text { After the assignment period, the students submit their final product. The quality of this } \\
\text { product and the opinions fall under the category "Quality". } \\
\text { The initial goals of the companies described in Table } 1 \text { were reportedly all achieved. } \\
\text { Companies' expectations of the final product's quality were either met or exceeded. } \\
\text { Workload that the students had to endure were, according to two of the three } \\
\text { interviewed companies, found to be adequate. }\end{array}$ \\
\hline Execution & $\begin{array}{l}\text { The course of the assignment and the general progress of the project is displayed in this } \\
\text { category. } \\
\text { During the assignment there were a few challenges. As seen under the category } \\
\text { "Execution" in Figure 2, the assignment was unclear. Other than that, not many } \\
\text { obstacles were faced. The companies had to give less guidance than initially expected. }\end{array}$ \\
\hline Communication & $\begin{array}{l}\text { This category is split in two sub-categories: communication between student and } \\
\text { company and communication between school and company. } \\
\text { Communication with the students went better than expected. Many statements were } \\
\text { made about communication being accessible, open and adequate. However, } \\
\text { communication between the school and company could use improvements. According } \\
\text { to the companies, the communication with school started too late. }\end{array}$ \\
\hline Effort & $\begin{array}{l}\text { The endeavors of both the school and students in the project are given in this category. } \\
\text { Similar to the communication category, this category is also split into two sub- } \\
\text { categories. } \\
\text { The companies spoke positively on the effort of the students. According to the } \\
\text { companies, the students were eager to learn and worked independently. } \\
\text { The endeavors of the school were a point of improvement. Two companies indicated } \\
\text { that the school's guidelines and criteria for the assignment were not clear enough. }\end{array}$ \\
\hline
\end{tabular}

\subsubsection{Comparison between pre-and post-interviews}

The companies have been interviewed both prior and following the Professional Practice assignment. The initial expectations were in some instances successfully predicted, while in other cases the predictions differed from the reality.

Expectations which were successfully predicted include:

The set goals, all companies indicated that their goals were achieved at the end of Professional Practice. Preparations, the companies did not have any alternate preparations they would have made in hindsight. Communication with the school, both prior to and post project there were difficulties in this regard.

In contrast, several aspects turned out different from the initial expectations. These include: The company expected a lack of knowledge from the students. This was not an obstacle.

Communication with students, which was better than initially expected.

Guidance for the students was less needed than was expected.

\subsubsection{Qualitative analysis student surveys}

The surveys post-project, which were mentioned in Section 2.2, contained some open questions to gain more input from the students. In the end 15 students filled in this survey. This is qualitative data that is analyzed, using the same method as described in Section 3.1.1. 


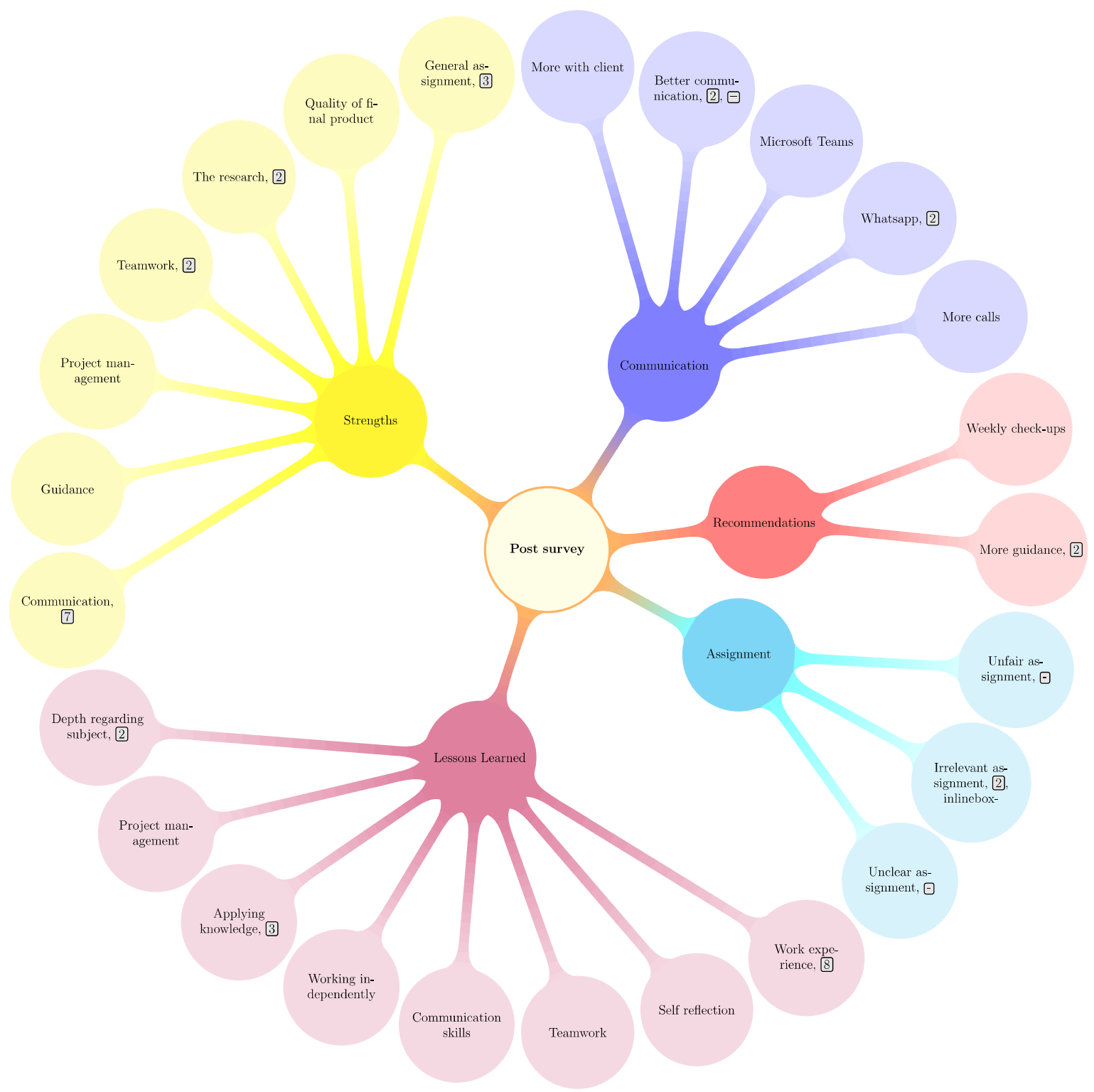

Figure 3. Mind-map of data from the student surveys. The numbers in the outer layers indicate how many times a statement linked to the displayed keyword appeared. The plus and minus symbols indicate whether this was used in a positive $(+)$ or negative $(-)$ context. 
Table 3. A summary of each keyword category as shown in Figure 3.

Communication This category depicts the communication during the assignment and the statements that were made regarding communication. The most frequently mentioned aspect that went well is communication. This was indicated by 7 of the 15 students. While communication was a frequently mentioned strength, two statements were made expressing that better communication between student and company was needed. Points of improvement relating to communication were more calls and more contact with the client. One more notable point is that several students resorted to using different methods of communication, such as Whatsapp and Microsoft Teams.

Strengths

Students were asked which aspects of the assignment went well. Their answers are displayed in the category "Strengths". This can contain strengths of PP, their collaboration with the company or assignment-specific aspects. Communication was the most frequently mentioned strength. Teamwork, conducting the research and the course of the assignment are other strengths that were often mentioned.

Recommendations The students' feedback after Professional Practice can help improve future assignments. Any recommendations that the students would implement are given in the "Recommendation" category.

The recommendation that the students would like to implement is more guidance from the company. One student indicated that weekly check-ups to track the progress of the assignment would help in this regard.

Lessons learned One of the questions on the survey was: "What are the (unexpected) things you learned during professional practice?". Answers to this question, and other statements relating to the development of the student are depicted in this category.

Students mentioned that they learned a lot of different skills during PP. Most notably is that 8 of the 15 students said they have gained more work experience. Another thing which was frequently mentioned, was that students learned to apply their study knowledge in the work field. Other skills that the students learned were teamwork, selfreflection, communication skills and many more which can be seen in Figure 3.

Assignment Points of improvement, statements and/or opinions on the assignment are shown in the category "Assignment". This can include assignment workload, clarity, relevance and efficacy.

The most encountered obstacle was the lack of relevance and clarity of the assignment. In one instance, a student expressed that the workload across students was unequal.

\subsubsection{Comparison between post-surveys and post-interviews}

Since both the post-survey (Section 2.2) and the post-interview (Section 2.1) are done after the assignment, they can easily be compared. This comparison gives insight in both the students' and companies' perspective of PP. Looking at both perspectives will create a more complete picture and reveal possible points which can be improved or should be capitalized on.

When looking at Figures 2 and 3, several connections and patterns start to show. Some of the aspects where both student and company agree on are:

Communication, both parties were positive in this regard. The similar opinions are shown in Figures 2 and 3 under the communication categories.

Quality of the final product, which was a strength mentioned by both students and companies (Figure 2, Quality; Figure 3, Strengths).

Clarity of the assignment, according to both students and companies this is a point of improvement (Figure 2, Effort; Figure 3, Assignment).

There are differences in views of the students and companies. These differences are:

Recommendations, students stated as a recommendation that they needed more guidance while companies had no further recommendations (Figure 3, Recommendations).

Communication with the school, companies had obstacles in this regard while students did not (Figure 2, Communication).

\subsection{Quantitative analysis}

3.2.1 Comparing pre- and post-survey data

The students were asked to fill out surveys at the start and end of the project. As explained in Section 2.2, students rated statements by choosing an integer score in the range of -2 to 2 . 
The average scores of the identical questions in both surveys (11 questions in total) were analyzed using an independent sample $t$ test. The goal of this test is to see if there was a significant difference in the average scores between both surveys. However, assuming equal variance, none of the answers to these 11 questions were significantly different between the pre- and post-surveys, meaning that the opinion of the students did not change during the PP project.

3.2.2 Analyzing post-survey data

The average scores of the post-survey were compared with the expected average score of 0 through the use of a one-sample $t$ test. The results that significantly diverged from 0 are shown in Figure 4.

\section{Questions}

1. I want and will learn a lot about the relevant knowledge.

2. Did the communication between you and the company go well?

3. I think that this type of program is useful in order to improve my

knowledge.

4. Do you think that the PP is a good education method?

5. I can learn some knowledge and skills in this type of program

The participation in Professional Practice can bring me some

interesting and useful information.

7. I am confident to complete this kind of project with success.

8. How often did you send messages in order to communicate?

9. Did you ask enough questions and did you ask for feedback?

10. I would like to participate in this type of program.

11. This type of program is fun.

12. Were the instructions of the company clear?

13. I am aware of the mechanics to run this kind of project.

14. I want to participate in this type of program more and as soon as it possible.

15. I forgot about time passing while participating in the project.

16. I temporarily forget worries about other things while I participated in the project.

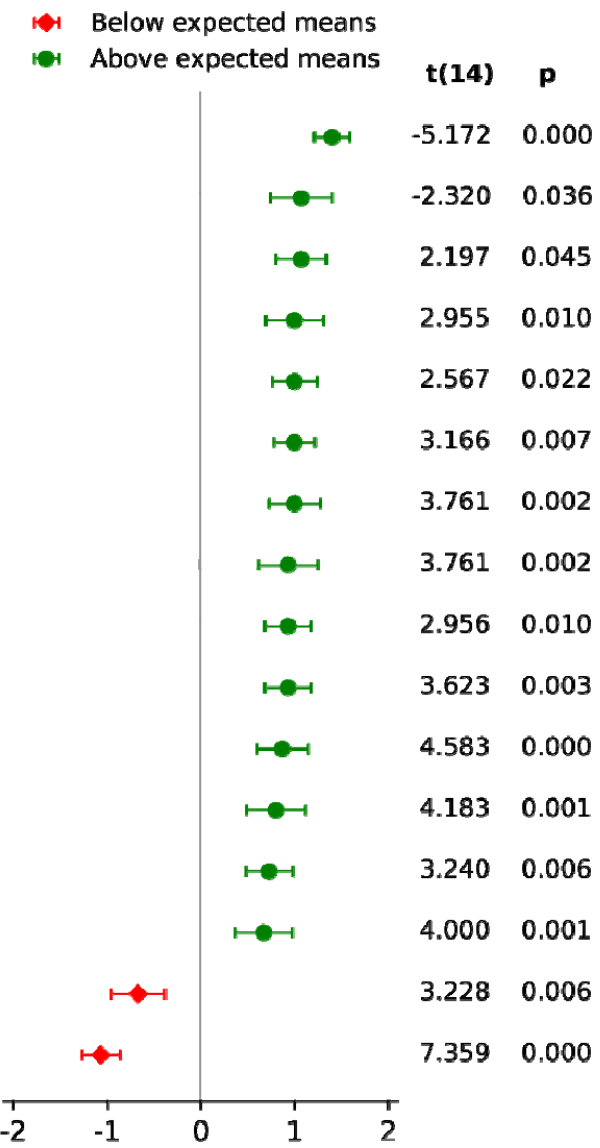

Figure 4. The results of a one-sample $t$ test of the post-survey data, which compares the scores with an expected value of 0 .

In Figure 4, question number 1 has not only the highest average score, but also the smallest standard error of the mean. Questions with average scores that were not significantly different from the expected average are not included in this figure. The two columns on the right show the t-statistic (with 14 degrees of freedom) and pvalue or two-tailed significance. Questions 2, 8, 9 and 12 are about communication (blue). Questions 1, 3 and 6 are about the lessons the students learned (purple), and question 13 is about the expected challenges (green). 14 out of 16 questions scored significantly higher than the expected average score, while 2 scored significantly lower. These low scoring questions, numbered 15 and 16 in Figure 4, are about forgetting about time passing or about other worries during the project. The intent behind these questions was to determine how engaged students were with their projects. The low average scores indicate that students were less engaged with the project than expected.

Nevertheless, the other 14 questions scored higher than the expected average. This includes questions with subjects such as motivation, confidence, perceived usefulness, perceived educational value, enjoyment and the students' intention to participate.

\subsection{Comparison between quantitative and qualitative results}

As mentioned in Section 3.1.5, one of the aspects that students and companies agreed on was that they were positive about their mutual communication. This result of the qualitative analysis also appears in the quantitative analysis, where the questions highlighted in blue in Figure 4 were about communication and scored above the expected average. 
In the category "Lessons learned" in Section 3.1.5, the students expressed that they gained experience and learned new skills due to their project. This corresponds to the above expected average scores for questions highlighted in purple in Figure 4.

As shown in Section 3.1.3, the companies expected a lack of knowledge from the students. This was not an obstacle. This fits with question 13 highlighted in green in Figure 4.

\section{Conclusion and recommendations}

The main research question was "What are the best practices to improve collaboration during PP". To answer this question, the results of the analyses were inspected.

Looking at the results of Section 3.1, several positive points of PP are revealed. The most notable of which were: Communication between student and company.

Achievement of set goals.

Quality of the final product.

In contrast, there were also some points of improvement which were frequently mentioned. These are:

Clarity, relevance and fairness of the assignments and its guidelines.

Guidance from the company to the students.

Communication between the school and company.

Using this feedback, several practices can be deduced which can help the collaboration during Professional Practice.

To start, the assignment criteria should have clear and concrete guidelines for the companies to follow. For the companies, these guidelines should include the requirements their assignment has to meet. For the students, the guidelines should incorporate the workload of students and the relevance to their study.

The students had as recommendation more guidance from the company. One statement mentioned that weekly check-ups would help in this regard.

According to the companies, the communication with the school started too late and was an obstacle during the assignment period. Concrete agreements prior to the assignment would help reduce the difficulties caused by this.

Several students indicated they preferred to communicate using alternative platforms, such as Whatsapp and Microsoft Teams. Incorporating this in PP could help strengthen the communication between companies and students.

\section{Limitations and future research}

During the analysis of the interviews and the surveys a number of limitations came to light. First of all, the majority of the survey questions were originally composed in English and then translated to Dutch. This could have led to some students misinterpreting one or more of the questions.

Another limitation was that while 78 students participated in the Professional Project, only 16 and 15 students filled out the pre- and post-survey respectively. Of these students, only 4 students filled out both surveys. This small sample size limited the number of statistical tests that could be used for analyzing the results. Future researchers that look into this topic should take these limitations into account when collecting their research data.

The interview and survey questions used in this case study can be found at https://bit.ly/3kmo8Kl. Future research could include a larger study comparing results over multiple years, as well as once recommendations have been implemented. A pre and post recommendation implementation study would allow researchers to understand the degree to which recommendations impact outcomes such as student and company satisfaction with aspects including communication and student guidance.

\section{References}

Ankrah, S. \& AL-Tabbaa, O. (2015), "Universities-industry collaboration: A systematic review", Scandinavian Journal of Management, 31:387-408.

Chandrasekaran, S., Stojcevski, A., Littlefair, G. \& Joordens, M. (2013), "Project-oriented design-based learning: aligning students views with industry needs", International journal of engineering education, 29(5):11091118.

Crosthwaite, C., Cameron, I., Lant, P. \& Litster, J. (2006), "Balancing curriculum processes and content in a project centred curriculum: In pursuit of graduate attributes", Ichem, Education for Chemical Engineers, 1(0): 1-10.

Davis, G. A. (2002), "Using a retrospective pre-post questionnaire to determine program impact”, ERIC.

Dunne, E. \& Rawlins, M. (2000), "Bridging the gap between industry and higher education: Training academics to promote student teamwork", Innovations in Education and Training international, 37(4):361-371.

Etzkowitz, H. \& Leydesdorff, L. (1995), "The triple helix-university-industry-government relations: A laboratory for knowledge based economic development”, EASST review, 14(1):14-19. 
Goldsmith, R., Reidsema, C., Campbell, D., Hadgraft, R. \& Levy, D. (2011), "Designing the future", Australasian Journal of Engineering Education, 17(1):1-9.

Ivascu, L., Cirjaliu, B. \& Draghici, A. (2015), "Business model for the university-industry collaboration in open innovation", 3rd GLOBAL CONFERENCE on BUSINESS, ECONOMICS, MANAGEMENT and TOURISM.

Kobayashi, Y. (2020). Non-globalized ties between Japanese higher education and industry: crafting publicitydriven calls for domestic and foreign students with global qualities. Higher Education, 1-13.

Mills, J. E. \& Treagust, D. F. (2003), "Engineering education-is problem-based or project-based learning the answer?", Australasian Journal of Engineering Education, online publication 2003-04.

Rosemann, M., Sedera, W. \& Sedera, D. (2000), "Industry-oriented education in enterprise systems", In Australasian Conference on Information Systems ACIS, Brisbane, Australia.

Rynes, S. L., Bartunek, J. M. \& Daft, R. L. (2001). “Across the great divide: Knowledge creation and transfer between practitioners and academics", Academy of management Journal, 44(2):340- 355.

Sageev, P. \& Romanowski, C. J. (2001), “A message from recent engineering graduates in the workplace: Results of a survey on technical communication skills", Journal of Engineering Education, 90(4):685-693.

Slotte, V. \& Tynjälä, P. (2003), "Industry-university collaboration for continuing professional development", Journal of Education and Work, 16(4).

Tamim, S. R. \& Grant, M. M. (2013), "Definitions and uses: Case study of teachers implementing project-based learning", Interdisciplinary Journal of Problem-Based Learning, 7(2):72-101.

Uziak, J. (2016), "A project-based learning approach in an engineering curriculum", Global Journal of Engineering Education, 18(2):119-123.

Vande Wiele, P., Morris, D., Ribire, V. \& Ermine, J. (2017), "Project based learning for professional identity: A case study of collaborative industry projects in marketing", The Independent Journal of Teaching and Learning, 12(2):45-63.

Wrzesien, M. \& Raya, M. A. (2010), "Learning in serious virtual worlds: Evaluation of learning effectiveness and appeal to students in the e-junior project", Computers \& Education, 55(1):178- 187. 